\title{
ELECTRICAL REQUIREMENTS OF CERTAIN MACHINES IN THE RUBBER INDUSTRY
}

\author{
BY C. A. KELSEY
}

This paper is intended to outline briefly the power requirements of some of the principal machines which work up crude rubber and render it suitable for the manufacture of various articles.

The principal source of rubber is the wild trees of Brazil, although cultivated rubber in increasing quantities is now produced in East India, Ceylon, Malayan Peninsula and Southern Mexico. The former reaches the factory in the form of balls or biscuits about a foot in diameter. Cultivated rubber is universally washed and sheeted at the plantation and is shipped in the form of cakes of folded sheets.

Washing. After the biscuits have been cut into chunks and softened in a bath of warm water, they are fed into a cracker or rough washing mill. This mill consists of two or three rolls between which the rubber passes, is torn apart and rolled out into a rough sheet. Water flowing through the rubber in its passage through the rolls washes out part of the entrapped dirt.

These mills run at a constant speed of 20 to $25 \mathrm{rev}$. per min. The load is very irregular and depends upon the feeding of the mill. A three-roll washer with continuous feeding requires an average of 25 to 35 h.p., with power peaks of 100 h.p.

The rough sheet is then passed through a single set of rolls where it is further washed and rolled out into a sheet or " crepe."

These mills run at a constant speed of about 25 rev. per min. The load is fairly uniform as the rubber is already in the form of a rough sheet. The power required averages 20 to 25 h.p. and 
occasionally runs up to 50 h.p. when the sheet is introduced between the rolls after being doubled.

After the crepe has been dried either in a drying room, where it is suspended from the ceiling, or placed in a vacuum drier, it is ready to be masticated and mixed with the suitable ingredients to form various compounds.

Masticating. The dried crepe must be worked or masticated into a homogeneous and plastic state before the ingredients are added. This is most economically done in a shorter mill than a mixing mill. The power required at the beginning of the process is greater than at the end and runs up to a high value as the rubber is cut free from the roll and doubled back in again. From tests on a 50 -in. $(1.27-\mathrm{m}$.) face mill the average power was 37 h.p. and the maximum 74 h.p., while a 60 -in. (1.52-m.) face mill required an average power of 90 h.p. and a maximum of 140 h.p.

Mixing. Pure rubber is never used in the manufacture of rubber articles without first adding to it some other substance. Different materials are employed, depending upon the use and desired characteristics of the rubber product. Some materials increase the elasticity, some impart hardness and toughness and some act as mechanical fillers to cheapen the product without materially affecting the desired characteristics.

Where the rubber is masticated in the mixing mill, the predetermined weights of the various substances are added in a powdered or liquid state only after the masticated rubber has been thoroughly worked and warmed. As the ingredients impart different degrees of hardness and toughness to the final product so will the power to drive the mill vary.

The speed of the rolls ranges from 20 to $25 \mathrm{rev}$. per min. A 40 -in. (1-m.) face mill requires about 20 h.p. average and 40 h.p. maximum on relatively soft compound and $25 \mathrm{~h} . \mathrm{p}$. average and 55 h.p. maximum on hard compound while a 60 -in. $(1.5-\mathrm{m}$.) face mill requires 55 h.p. average and 120 h.p. maximum on medium compound.

Refining. In some installations the compound after leaving the mixing mill is passed through machines that strain it and reduce it to a very thin sheet. The strainers are in principle like a meat grinder. A feed screw revolving inside a waterjacketed cylinder forces the compound through a fine mesh screen which is backed up by a perforated plate. This removes all solid foreign objects which ordinarily find their way into the 


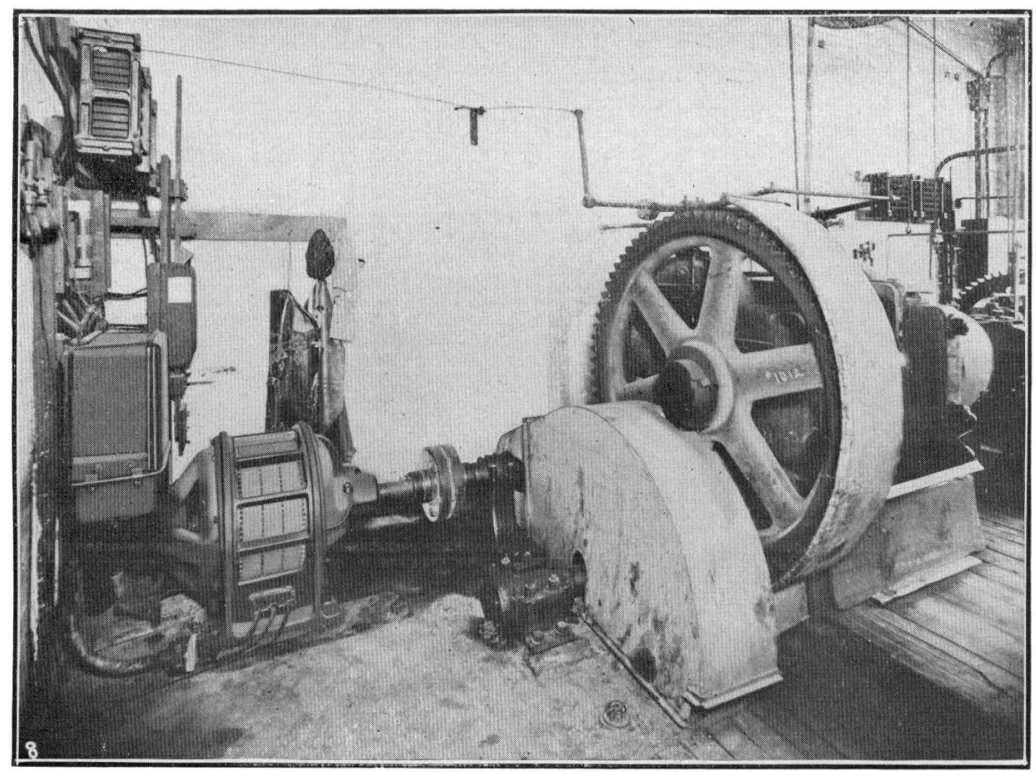

Three Roll Washer

[KELSEY]

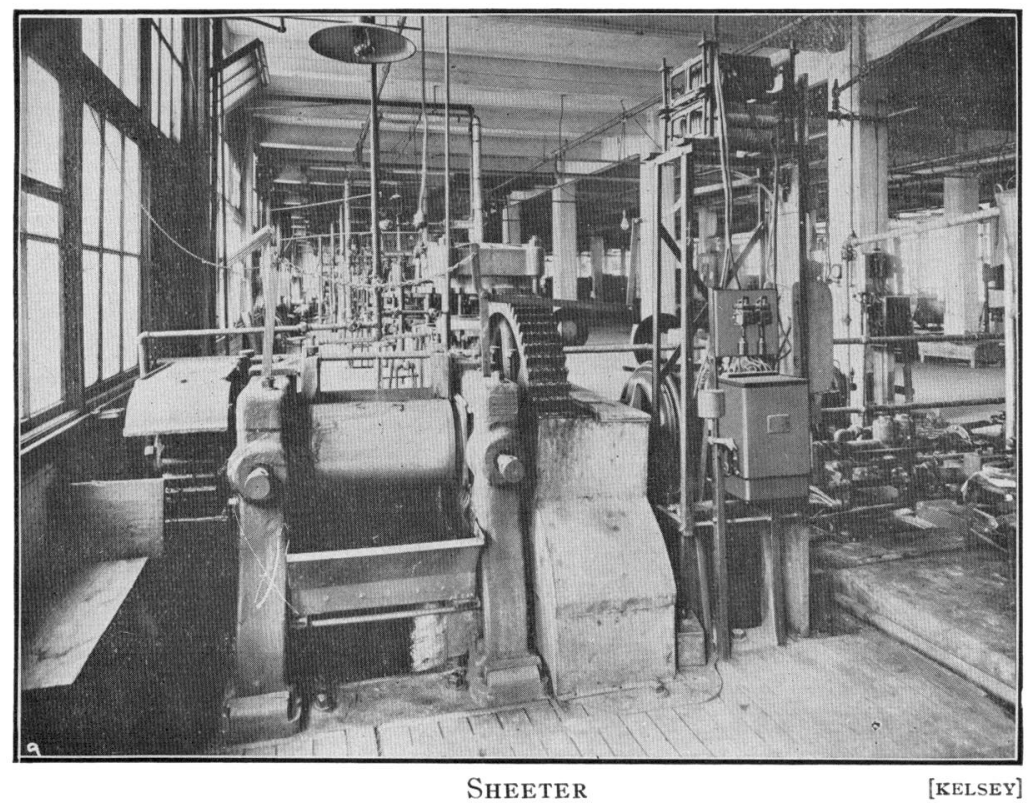


PLATE XXXVI

A I. E. E.

VOL. XXXII, 1913

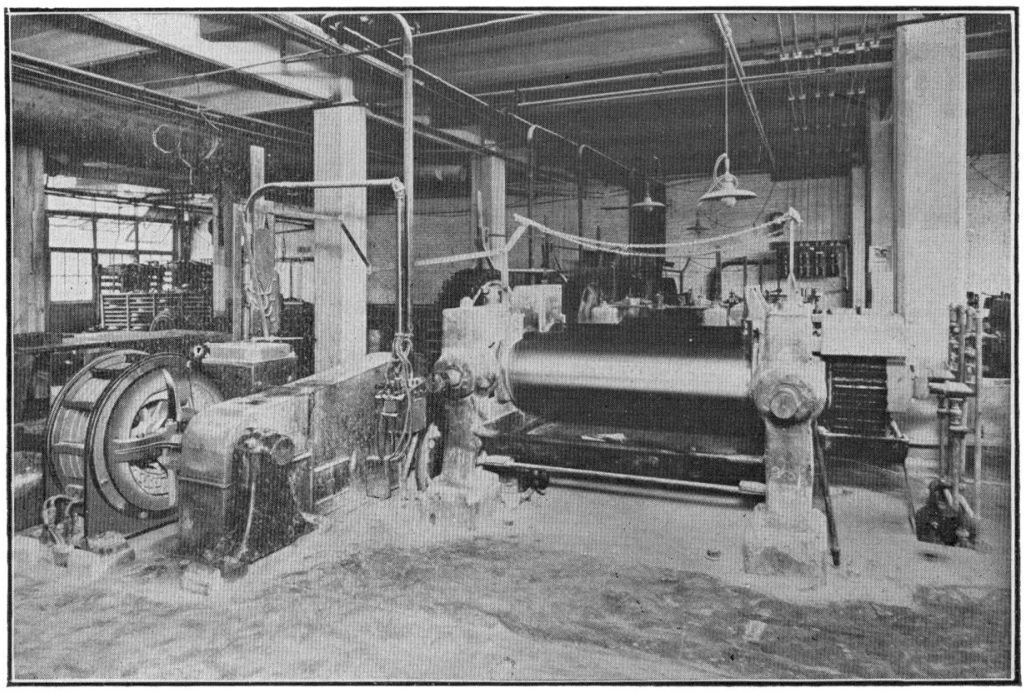

Mixing Mill

[KELSEY]

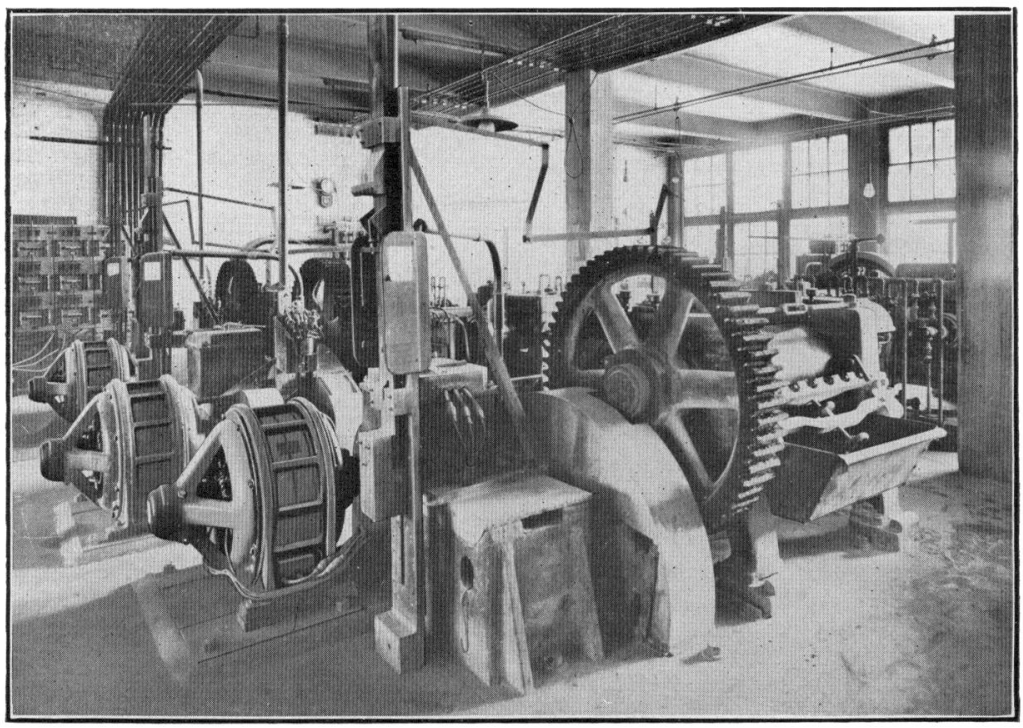




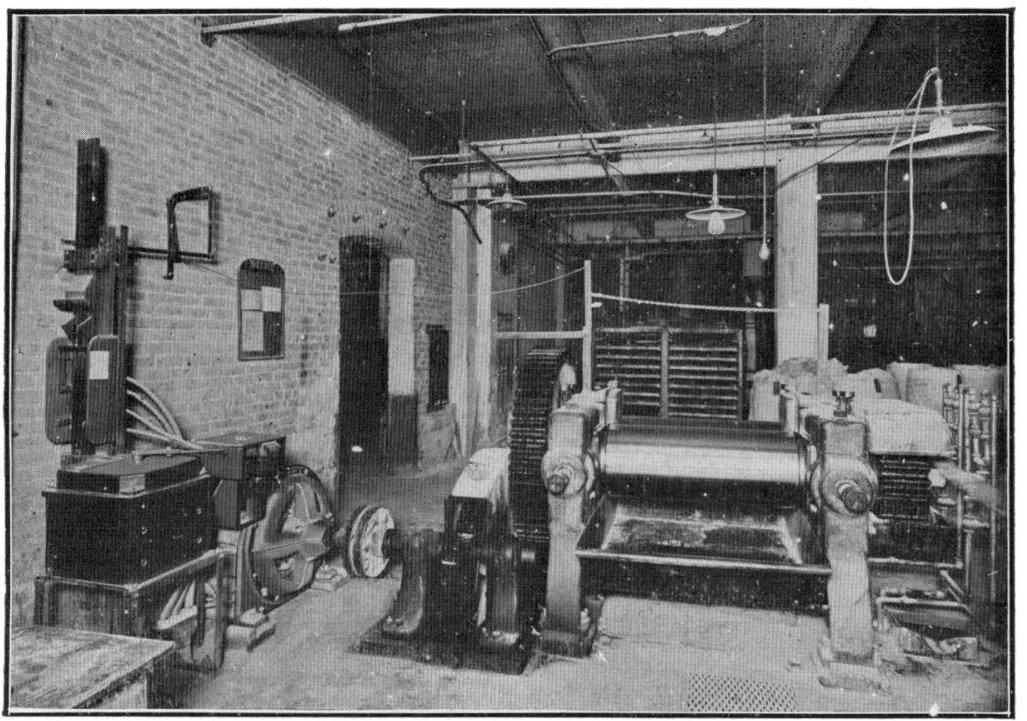

WARMING MILL

[KELSEY]

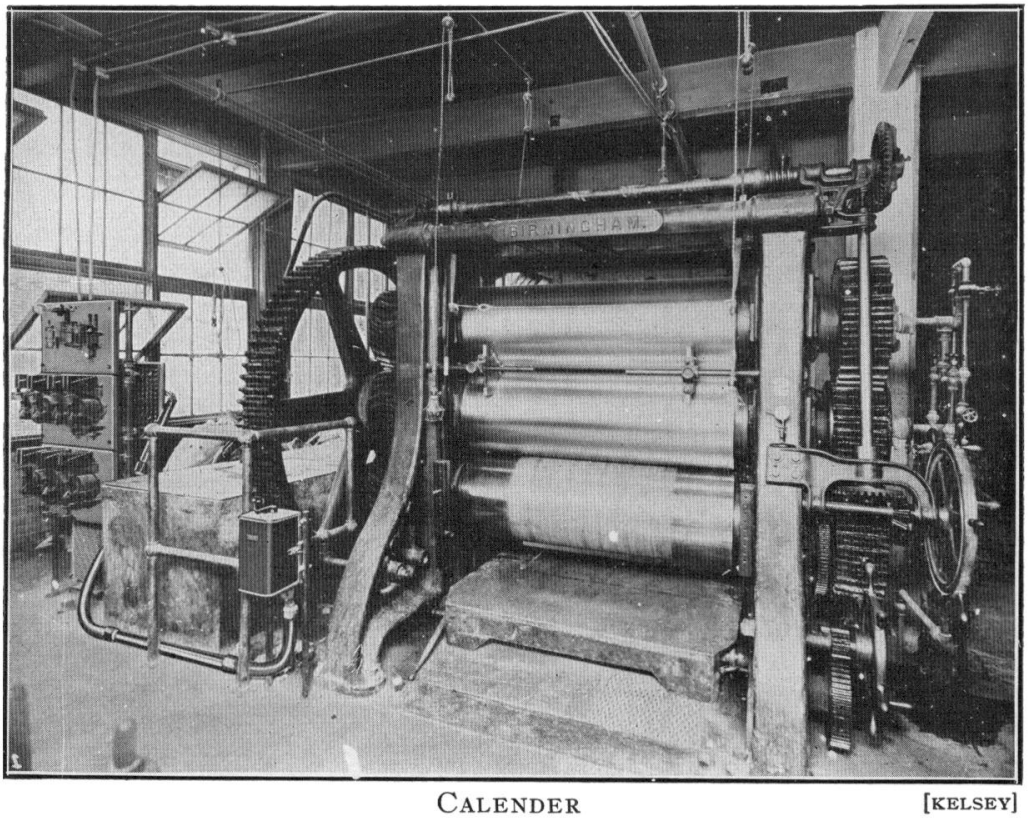


material. The compound becomes heated more or less as it passes through the strainer and the final temperature must be kept below a given value. The heating varies with the compound and the initial temperature. An efficient means of maintaining maximum output is to vary the speed. This therefore requires an adjustable-speed motor. A two-to-one speed range is sufficient. The power required is $25 \mathrm{~h}$.p. over the whole range. The harder compounds, requiring high torque are run at the slow speeds and the soft compounds requiring less torque are run at the high speeds.

After passing through the strainers the compound is passed through a refiner, which is a small mill whose rolls are held very close together. The compound is run through at a thickness of approximately three mils, being passed through several times and finally scraped off the roll as it comes through. It is then bundled up and is ready for the warming mill.

The mills are run at constant speed and uniform load. The power required does not exceed 25 h.p.

Warming. Although the compound is warmed in the mixing mills, it cannot always be used at once in the calenders, and, moreover, it is beneficial to the compound to let it season before calendering. Warming mills are therefore essential to warm the compound when it finally comes to the calenders. These mills are identical with the mixing rolls except that they are equipped with steam-heated rolls. The power required is slightly less than for the mixing rolls.

Tubing. When the article to be produced is tubular or ringshaped the compound is forced through tubes. This machine is similar to a strainer excepting that instead of a screen and perforated plate the machine is fitted with a disk which delivers the compound in the form of a tube.

The speed and power requirements approximate those of a strainer.

Calendering. Practically all rubber compounds, with the exception of those run through tubes and for the manufacture of molded articles, are sheeted in a calender.

This machine has a series of rolls two or four in number arranged one over the other, between which the compound is passed to form a sheet. The surface of the rolls is finished smooth and the space between the rolls is adjustable to a very fine degree. The rolls are fitted with steam and water connection to heat or cool the compound as required. 
The power required to drive a calender varies over a wide range depending on the character of the compound, thickness, width and speed. The speed is limited to that at which the compound can be run without blistering or the forming of a rough surface. When the calender is started up with cold rolls the permissible speed is higher than after the cooling rolls become heated. As these rolls become heated, it is necessary, in order to obtain the desired surface of the sheet, to reduce the speed. A fine speed graduation is therefore necessary to maintain a maximum output. The torque required depends upon the thickness and material and there are so many combinations possible together with the speed requirements that it is difficult to formulate any rule to determine the power. The motor must be large enough to meet the extreme conditions.

From a number of tests made it is found that an 18-in. (45.6$\mathrm{cm}$.) diameter, 40-in. (1-m.) face, three-roll calender running at a surface speed of $37 \mathrm{ft}$. $(11.2 \mathrm{~m}$.) per minute, requires an average of 20 h.p. A 24 -in. $(60-\mathrm{cm}$.) diameter, 48 -in. $(1.2-\mathrm{m}$.$) face$ three-roll calender running at a surface speed of $35 \mathrm{ft} .(10.6 \mathrm{~m}$.) per minute requires an average of 35 h.p. and a 22 -in. $(55.8-\mathrm{cm}$.) diameter, 65 -in. (1.64-m.) face, threc-roll calender running at a surface speed of 36 feet. $(10.9 \mathrm{~m}$.) per minute requires an average of 45 h.p.

Some compounds that are run through the calender in successive layers which build up to $1 / 2$ inch $(1.27 \mathrm{~cm}$.) or even $3 / 4$ in. $(1.9$ $\mathrm{cm}$.) must be run at approximately $20 \mathrm{ft} .(6 \mathrm{~m}$.) per minute, while for "friction" work the speed of the driven roll may be $80 \mathrm{ft}$. $(24.3 \mathrm{~m}$.) per minute. The thick sheets will require slightly greater torque than the average thickness, while the torque for so-called "friction" work is considerably less.

The term frictioning is applied to that process performed by a calender in forcing a soft rubber compound into the meshes of cotton fabric. It is preliminary to the skimming or coating of the fabric. The rubber compound is very soft and plastic and is rubbed in by the action of the driven roll, which travels at a faster speed than the roll carrying the fabric.

As the compound and fabric are fed through in a continuous sheet the power required for a given material, thickness and width is quite uniform.

\section{Motor Characteristics}

In considering the power and speed requirements of the different machines, it is seen that the mills for working up the rubber 
and mixing it to form the various compounds, call for extreme overloads but of short duration. By grouping these mills and driving by a single motor the load peaks can be reduced. Instead of the maximum values being 200 per cent of the average, it has been determined that this can be reduced to 150 per cent by driving with one motor a group of six mills used for masticating, mixing and warming.

Where individual drive is used, alternating-current polyphase squirrel cage motors are best suited to carry the high load peaks. By grouping the mills, a motor of a smaller capacity than the aggregate of the individual motors can be employed. Moreover, synchronous motors can then be installed and assist in correcting the power factor of the general power load. The mills are generally equipped with jaw clutches which can be open or closed while the shaft is running. The synchronous motor can thus be disconnected from the mills at starting. The selection of squirrel cage or wound rotor induction motor depends upon the local starting restrictions, as the squirrel cage motor will easily bring the shaft up to speed even with all mills connected.

Direct-current motors are sometimes used when this is the power available, but they are more expensive and not so well suited to the load conditions.

The calenders, as mentioned, require close speed control over a range of four to one. This can best be accomplished by a direct-current motor, which is the general practise. A number of schemes have been employed to accomplish this. Among them might be mentioned the multi-voltage and adjustable voltage methods.

The motor is excited at constant field strength and the armature supplied with a variable voltage. This variable voltage can be produced by a series of different voltage generators or by a rotary compensator or booster set.

A modification of the preceding is a three-wire, two-voltage source of armature supply combined with adjustable speed by field control. The first-mentioned methods produce a wide speed range but are expensive because of the number of machines required for each calender. The second method produces a less speed range but is less expensive, particularly where a large number of calenders are installed.

With the more recent general application of commutating poles to direct-current motors a greater speed range is permissible with constant armature voltage and varying field strengths.

This last-mentioned method results in the simplest equipment 
as a whole. The motor must be larger but is therefore more substantial, while the control can be made extremely simple, or it can be made entirely automatic, thus calling for a minimum of attention and care from the opcrator.

The tubers also require a direct-current motor and the lastmentioned method of speed control is particularly adapted to these machines.

As the power to drive the mills is by far the greatest portion of the total power, alternating current will generally be selected. This therefore requires a motor-generator set or synchronous converter to deliver direct current to the calenders and tubers. These machines can be used to correct the power factor of the general power circuit.

\section{Motor Control}

As the motors to drive the mills are run at constant speed, starting devices only are required. A speed-controlling device must, however, be furnished with the motors driving the tubers and calenders. The former machines are simple in operation and a controller for hand operation which combines starting and speed adjustment is sufficient. The calenders, however, require closer attention and must be capable of starting and stopping by the simplest means on the part of the operator. This is best met by a control which enables the operator to bring the calender up to speed by moving the controller handle around to obtain the desired speed. Automatic acceleration should be provided to limit the current input while the controller handle is being moved around. It should then be possible to shut the calender down by pushing a button located on the calender. The speed of the calender should be retarded by dynamic braking of the motor. This is to provide a safety feature in respect to the operator in casc his hand should be caught between the rolls. Also, it is desirable to stop quickly to save material otherwise wasted by the coasting of the motor. It should then be possible to bring the calender up to the same speed as before by pushing a button on the calender. Means should be provided for reversing the direction of rotation of the motor to assist in manipulating the calender and also in case anything should be caught between the rolls and it becomes necessary to back it out. The control should also include overload and low voltage release features and be immune from damage to itself or the motor in case the operator fails to close or open the proper switches. 
Discussion on "The Behavior of Synchronous Motors During Starting" (Newbury), "Commutating Pole Saturation in Direct-Current Machines" (Stokes), "Constant Voltage Transmission" (Dwight) and "The Industrial Use of Synchronous Motors by Central. Stations" (Parker), Cooperstown, New York, June 25, 1913.

William J. Foster: The self-starting synchronous motor has one bad characteristic and that is the induced potential across the field terminals. It is something which exists in the nature of the apparatus. Of course, if we keep down the number of turns in the field winding, we always can help out in the matter of induced potential, but, as is stated by Mr. Newbury, it is not always convenient to do this. As a general rule, 125 volts has been regarded as standard, and we can design and wind the fields and insulate them so as to take care, ordinarily, of 125 -volt windings, but when it comes to 250 volts it begins to be a serious matter. The insulation problem is serious. In such cases I have known of this scheme of short-circuiting the field to have been the practical solution of the problem, but in general, as pointed out by the author, the short-circuiting of the field detracts from the starting torque per input. That being the case, it is extremely desirable to excite at lower potential.

There is a particular use which can be made of the short-circuited field that I have known to have been resorted to in a number of cases of motors that have an increasing torque from rest to synchronous speed, and that is to short-circuit the field when about two-thirds speed has been attained. By doing that the torque can somewhat be increased at the higher speed, before you reach the point where excitation can be applied.

I think there are many places where synchronous motors are now installed and some difficulty, perhaps, is experienced in starting up at the pulling-in point, where by installing a resistance and short-circuiting the field much better results can be obtained.

August H. Kruesi: I want to suggest that the author give us the number of slots per pole, the radial depth of air gap and the number of bars in the short-circuiting winding for both machines so that we can tell to what extent the performance depends upon the particular design of the machine tested.

F. D. Newbury: The number of armature slots per pole is twelve, and the radial depth of air gap $3 / 16 \mathrm{in} .(4.76 \mathrm{~mm}$.) The number of damper bars per pole is seven and the damper winding is of the same type as shown in Fig. 1. The armature slot pitch is $0.88 \mathrm{in}$. (22.35 mm.) and the damper slot pitch is $1.15 \mathrm{in}$. (29.2 mm.)

H. M. Hobart: Mr. Stokes's paper draws attention to one of the greatest difficulties in connection with the design of machines with commutating poles. The commutating pole certainly 
has been of very great service in improving the design of commutating machinery, but there are two sides to the matter and it has always seemed to me that it should not be used to any greater extent than is necessary for the accomplishment of the purpose for which it is put there. At its advent. designers used it to a very great extent and overdid the thing. The reasoning was that since with the commutating pole one could offset very large reactance voltages in the coil undergoing commutation, there was no need for any great subdivision of the commutator. It was considered that by having fewer segments and cheapening the construction of the commutator one could get as good results by neutralising the reactance voltage in the short-circuited coil by appropriately designed commutating poles, but it soon became apparent that there would be a tremendous magnetic leakage from these small commutating poles to the large main poles. Some designers appreciated that, but they were in a small minority. Most designers made the commutating poles the full length of the machine, but, as Mr. Stokes points out, there is 200 or 300 per cent magnetic leakage under these circumstances, unless you are quite careful in the design of the machine.

I considered right from the beginning, that the use of the commutating pole should be as follows: to design the machine as well as you could, quite aside from the commutating pole, and then put in enough commutating pole to neutralize the amount of reactance voltage, which you ordinarily have in the machine, or as much of it as is necessary to insure good commutation. My experience has been that it has usually worked out admirably to have the commutating pole extend only a very short distance in a direction parallel to the shaft. Make it as short as possible for the requirements. One should follow the procedure of first designing the machine as good as possible, without any reference to the intention which you have in reserve of adding the commutating pole.

Designers have been tempted to employ high reactance voltages. If, for example, a machine were planned with a reactance of 4 volts in the short-circuited coil, it might require that the commutating pole should extend the full width of the machine. If, however, a better design had been employed and the reactance voltage had been limited to 2 volts, then the machine could have been fitted with commutating poles of only half as great a length. This would have resulted in reducing the magnetic leakage and in less obstruction to the circulation of air amongst the poles.

Even at this late date, although the commutating pole has been used extensively for 10 years, there is still great need to emphasize this viewpoint. I am interested to see that the matter is being reduced to quantitative constants that will be of great aid, I have no doubt, to the designer.

F. D. Newbury: My own experience with direct-current design has been largely second-hand, and the experience I have 
had has been in connection with alternating-current problems. It has always seemed to me that designers of direct-current machines have been more inclined to approach their problems through empirical methods than have designers of alternatingcurrent machinery. Possibly this is due to their older experience, and the further distance they are away, in their methods, from the simple fundamentals. That at least has seemed to be the tendency.

It is the greater pleasure, therefore to note that in the present paper the author has got down to fundamentals, has made up his formulas from the results of careful experiment, and has approached the subject from the scientific and physical standpoint rather than from the empirical.

While the paper is primarily of interest to the designer, it is, I think, also of interest to the men using direct-current apparatus. There is a direct and particular relation between the commutating pole saturation and the ability of a given machine to withstand heavy overloads. It is, of course, on overloads that the saturation of the commutating pole becomes apparent and the non-compensated reactance volts cause dangerous sparking. All direct-current machines, even the compensated type, will flash on dead short circuit where the current will be anything from 15 to 20 times full load current. I have had many tests made, which have borne out the statement that most machines will flash very seriously with currents from five to ten times full load current. Those machines in which the commutating poles have been liberally proportioned, and more important still, as Mr. Hobart pointed out, machines in which the reactance volts have been made a minimum are the machines that will withstand the heaviest shocks and behave best on short circuits.

J. M. Hipple: In connection with Mr. Hobart's remarks, I call to mind a very extensive series of tests which showed clearly the advantage gained by the use of commutating poles. This test was made to determine if the commutating pole had any logical use in constant speed motor design. For some time its usefulness in adjustable speed motors had been conceded. A considerable number of representative motors of various makes were given endurance tests under these three conditions:

1. Full load and normal voltage.

2. Full load and 10 per cent below normal voltage.

3. Full load, normal voltage and 15 per cent increased speed by weakening the shunt field.

The motors tested were all of the non-commutating pole type and under condition (1) practically all gave good results, while under conditions (2) and (3) burning and blackening of the commutator developed in time. Similar tests on a series of commutating pole motors showed that under all three conditions, the commutator showed no signs of blackening or burning. Conditions (2) and (3) are not to be considered abnormal and must be provided for and the commutating pole when properly proportioned takes care of them perfectly. 
H. M. Hobart: Commutating poles are used as an antidote for certain troubles, and if the antidote is used to too great an extent it may cause a condition which is worse than that which it was designed to cure. That is the point.

John M. Hipple: There are two ways of considering the commutating pole, one as an antidote for commutation troubles and another as a prime factor in design. In my opinion it has a proper and very important field as a prime factor in design, just as in the non-commutating pole motor the saturated pole tip is often used as a prime factor.

H. E. Stokes: In regard to Mr. Hobart's remarks on the short interpoles, it seems to be the general experience that it is well to make them shorter than the armature, say about 50 or 60 per cent of the length of the armature, and that has the effect of permitting the heat to get away from the armatures as $\mathrm{Mr}$. Hobart pointed out. Something can be done to get away from the leakage question by making the interpole shorter, as regards the armature, and lengthening it up near the frame.

In regard to what $\mathrm{Mr}$. Newbury had to say about machines flashing over, whether they are compensated or not, that is mostly due to the commutating pole flux lagging behind the reactance voltage, which causes a flash-over which can scarcely be taken care of by the commutator form.

F. D. Newbury: Mr. Dwight's paper presents very clearly the advantages of synchronous condensers in holding constant voltage at the end of a long transmission line. There is one application which I understand has already been made where such a use of synchronous condensers was a necessity-the combination of a long line at high voltage and at high frequency so that operation with a light load at the receiving end made it absolutely necessary to install such synchronous condensers in order to hold the voltage down to normal, due primarily, of course, to the small generating capacity in comparison with the length of the line. In that case synchronous condensers of half the capacity of the generators at the generating station were installed. That is a special application of the general plan advanced by Mr. Dwight, and I am quite sure merely points the way to a more general use of such synchronous condensers. As Mr. Dwight points out, the use of such a large additional generator capacity can only be justified in the case of long lines, where the cost of the line will be a more important item in the total cost than the cost of the main and substation machinery.

Mr. Dwight refers to railway work as possibly the single exception to the general use of 60 cycles. I would point out that it is becoming more and more frequent to use 60 cycles for railway work, employing 60-cycle synchronous converters. In the work of one of the larger manufacturing companies it has become very apparent that the use of synchronous converters, in the smaller sizes up to $1000 \mathrm{kw}$, has gradually shifted from 25 cycles to 60 cycles; whereas a few years ago the $500-\mathrm{kw}$., 25 -cycle 
machine for example was built in large numbers, at the present time the 60 -cycle converter is the more usual machine, so that I think Mr. Dwight's single exception can be largely eliminated.

Mr. Dwight also has some misgivings as to the ability of such synchronous condensers operating at very low excitation for supplying leading current at no-load. I do not think any such fear need exist-practically any synchronous motor with a proper damper winding will hold up the voltage on poorly regulated systems at no load and very small excitation.

I ask Mr. Dwight if in his table on page 1556 the power factor at the generating station has been taken into account in determining the size and cost of the two schemes. In one case it is given as 99 per cent, while in the other it is given as 89 per cent. This difference of 10 per cent in the $\mathrm{kv}$-a. capacity will increase the cost for the constant voltage method, but it is a minor point in connection with the total saving incident to the system.

R. B. Williamson: Mr. Newbury's paper is an exceedingly valuable and interesting one, and particularly so to those engaged in the design of self-starting synchronous motors. The various oscillograms give a complete picture of the actions that take place during the different stages of starting and make many things plain which, while known to exist were not heretofore clearly understood. Some of the features brought out by $\mathrm{Mr}$. Newbury were touched on during the discussion of these motors at the meeting of the Institute held in April, 1912, in Pittsburgh, and the present paper clears up a number of points brought up at that time.

Mr. Newbury's conclusions drawn as they are from the very complete set of oscillograms leave little room for discussion. Some of the results obtained show that this class of motor is capable of performances at starting and pulling into synchronism much beyond the limits usually considered possible.

As regards starting from rest, the difference noted between the torque developed with the rotor winding open and closed is considerably less than most machines that have come under my notice. However, this is something that depends very largely on the design of the machine, and I agree with Mr. Newbury that except in cases where a very high starting torque is desired and where a high-resistance squirrel cage is used, it is possible and preferable to start with the field short-circuited through the rheostat though it may be necessary to open the field circuit later in order to prevent locking at half speed. I understand that the machines tested by Mr. Newbury had a laminated rotor spider; in machines having a cast-steel or cast-iron spider, the voltage induced in the open field winding is considerably less than when the field structure is laminated throughout.

An important feature brought out is that it is not necessary to have two starting points, provided the most favorable procedure is adopted when starting; and the deductions drawn from the oscillograms show the methods of starting and amount of 
excitation best suited to different starting conditions. Before the influence of field excitation on the momentary rush of current at change-over was discovered, there was considerable trouble with these motors due to tripping circuit breakers. The oscillograms show plainly why this was so.

To many who have not experimented with this class of motor it will appear surprising that $\mathrm{Mr}$. Newbury was able to pull loads practically equal to full load into synchronism. However, this is quite possible, although the large current required to do it must not be lost sight of, and in many cases this would preclude the use of the synchronous motor on such large starting load, unless of moderate size or operated on large systems where the current at starting was not objectionable. Fortunately, however, in many of the largest applications it is possible to reduce the pull-in torque required to a fraction of full load so that the starting current can be kept down. For example, air compressors can be unloaded, and centrifugal pumps can often be started with the discharge valve closed. Many of the early self-starting motors were made from parts originally designed for alternators, and did not give the best starting performance possible; but with careful design along the well-established lines of squirrel cage induction motors, starting pertormances comparing favorably with the induction motor can be obtained.

Mr. Newbury's paper deals with motors of the salient pole type and it may be of interest to mention some tests recently made on a small turbo-generator run as a three-phase self-starting motor. There has been, at least among some engineers, the opinion that the pulling-in effect is due partly to the fact that the poles are sharply defined, and that a machine having a cylindrical rotor without projecting poles and with a distributed field winding would be deficient in pull-in torque. Some tests were made with a small 125 -kv-a., 2300 -volt, 31.2 ampere, 3600-rev.per. min. turbo-generator having a smooth cylindrical rotor with 36 slots uniformly spaced around the circumference. The retaining wedges for the coils were of brass, and made connections at each end with bronze end bells, thus forming a uniformly distributed squirrel-cage.

It was found that with the field circuit open: this machine started with 280 volts applied to the stator and came up to speed in 54 seconds while drawing a current of 67.8 amperes. That is, the motor started on approximately $12 \frac{1}{2}$ per cent voltage and 2.2 times full load current. The power factor at starting was between 45 and 50 per cent. With the field short-circuited, there was very little difference in the starting performance: the voltage and current being practically the same as before. Tests were also made with various resistances ranging from $0.9 \mathrm{ohm}$ to $22.4 \mathrm{ohms}$ in the field, but there was very little change noticeable in the starting performance.

Some tests were also made to determine the load that could be pulled in. With 1130 volts (about $\frac{1}{2}$ voltage) applied to 
stator and with a field current of 19 amperes, it was possible to pull in a load of $32 \mathrm{kw}$. or about $25 \frac{1}{2}$ per cent of the rated output. The stator current just before synchronizing was 40 amperes or 1.28 times full load. Since the torque may be taken as approximately proportional to the square of the applied voltage, it is seen that this machine would probably pull in nearly full load if thrown over to full voltage. This was not tried in these tests on account of the loading arrangements not being suitable, but it is evident that the round rotor motor can pull in loads comparable with those handled by the salient pole machine.

H. M. Hobart: I share Mr. Williamson's views, and I am hoping that Mr. Newbury's paper will rather stir things up and make people take a little new courage in approaching the subject of the design of synchronous motors. It has gotten into a terrible rut, it seems to me. This is partly due to the cause to which Mr. Williamson alluded. Matters have drifted into having the design of synchronous motors handled by the same departments that handle low-speed alternating-current generators. Any proposition to consider the design of synchronous motors along the lines of the design of induction motors has always been handicapped by the necessity of a change of hands, as to who should design it, and bring about the evolution of the synchronous motor into a decent machine. It is at present an absurd caricature of what it might be and the tantalizing part of it is that there are several perfectly serviceable methods ready and waiting to be used, but you cannot get anybody to look at these methods, or incorporate them in their designs, simply because they are following the old cut-and-dried methods, and everybody turns a deaf ear to any propositions for improvement.

Mr. Williamson alluded to some very interesting departures which he has had in hand and which it seems to me should offer much promise, but there are also other methods which would also serve to render the synchronous motor an admirable machine and make of it a machine which could be more widely used, for the reason that it will tend to decrease the price at which power can be provided to the consumer, in many cases, because you can run your synchronous motor with a leading power factor. That is a very important point indeed.

I believe that the synchronous motor can be used to great advantage in much smaller sizes than has heretofore been considered desirable, in sizes which will lap over into the field that has been generally held by common consent to belong to the induction motor. If only the synchronous motor could be designed by induction motor designers, working on the lines which have enabled them to see just what is needed for these starting and running-up conditions, the result would be for the good.

The induction motor has the fault that if you give it high starting torque, with the squirrel-cage variety, that will be accompanied by low efficiency and considerable heating. It must have high resistance in the squirrel-cage rotor, for the purpose 
of giving the starting torque required in many special cases. This is an inherent characteristic of the motor. But in the case of the synchronous motor you can, in a sense, leave it behind when you synchronize the machine and have a highly efficient and cool-running machine for ordinary running, yet at the same time have a high starting torque, so that the synchronous motor, instead of being inferior in regard to its ability to have good starting torque characteristics, has an advantage over the induction motor in those respects. It ought to be associated in our minds as a characteristic of synchronous motors that they can be given better starting torque than induction motors, whereas we have just the other notion.

In reading over Mr. Dwight's paper, far too hurriedly, for so excellent a paper, it seems to me the nature of the results, and the careful calculations which he made, bring out much more strongly than they ever have heretofore been brought out, the advantages to be derived from this use of synchronous condensers in connection with long-distance transmission. The result is that the differences, expressed in percentages, are tremendous as regards extending the limitations. Why are we going to 100,000 and 150,000 volts? Because we have exhausted the possibilities of lower voltages in the matter of reaching out over wide areas and delivering energy at the limits of the system at a price which can compete with local plants. If, as Mr. Dwight's figures appear to show, you can, with a given voltage, if you operate on this principle, extend these limits 50 per cent, so that you can carry out at 100,000 volts, an undertaking in connection with which you would otherwise have to resort to 150,000 volts, you have just so far extended the limits, and when you are driven up to 150,000 volts, or higher, this further extension of the limits is still at hand.

As regards the amount of power transmitted, the distance to which it can be transmitted, and the price at which it can be delivered at a great distance, it would appear from Mr. Dwight's figures that the constant voltage method of working will lead to great extensions of the possibilities in connection with the electrical transmission of energy. It seems to me that the conclusions are very fairly and clearly stated, and that the paper is for this reason a very valuable one.

Lee Hagood: I have been very much interested in $\mathrm{Mr}$. Dwight's paper. It struck me that the most interesting feature of it was that he could work out so many results and come to such valuable conclusions by such very simple methods.

A short time ago I was identified with the design of a system in which we were laying out a 110,000-volt transmission line, and our starting point which had to be settled was: what would be the size of our synchronous condensers. The necessity for this arose because our load was chiefly an inductive one, and we could not proceed with the design of the system until we settled upon the difference in voltage between the generating and receiving 
stations at full load. Until this was settled, we were unable to fix the voltages and taps for the transformers and the kv-a. ratings to give our generators and transformers. Another point of considerable importance was the size of conductor. As the transmission line was very long, it was important, on account of expense, to use as small a conductor as was consistent with good engineering. All of these points revolve around the question of voltage difference maintained between the generating and receiving stations, because the power factor and efficiencies of the line have fixed relations depending upon the kilowatt load for a given voltage difference and line constants. The question of the size of synchronous condenser is dependent upon this and also upon the power factor of the load.

I note that Mr. Dwight does not take into consideration the charging current of the line. I think this can be neglected for lines under 60,000 volts, but I think for all long lines above this, it should be included.

(The lantern slides and explanations of them, included in $\mathrm{Mr}$. Hagood's discussion, will not be reproduced here, as they were used in connection with a paper presented before the Los Angeles and the San Francisco Sections, entitled Operation of Transmission Lines. It is published in this volume, p. 855.)

N. E. Funk: Referring to Mr. Parker's paper, I wish to call attention to the fact that even though we consider raising the power factor from a low value to unity, which is the worst condition so far as cost is concerned that can be imposed upon a synchronous condenser installation, the cost balance will still be on the right side of the ledger, as the following tabie will show.

\begin{tabular}{|c|c|c|c|c|c|c|c|c|}
\hline Load. & P. F. o & $\begin{array}{l}\text { P. F. of } \\
\text { Line }\end{array}$ & $\begin{array}{c}\text { Syn. } \\
\text { motor } \\
\text { capacity. }\end{array}$ & $\begin{array}{c}\text { Gen. ca- } \\
\text { pacity }\end{array}$ & $\begin{array}{l}\text { Cost of } \\
\text { gen. }\end{array}$ & $\begin{array}{l}\text { Cost of } \\
\text { motors }\end{array}$ & $\begin{array}{c}\text { Cost per } \\
\mathrm{kw} \text {. of } \\
\text { load }\end{array}$ & $\begin{array}{l}\text { Savings } \\
\text { per kw. } \\
\text { of load }\end{array}$ \\
\hline 100 & $80 \%$ & $80 \%$ & 0 & 137.5 & $\$ 10,312.50$ & 0 & $\$ 103.125$ & \\
\hline 100 & $80 \%$ & $100 \%$ & 60 & 104.93 & $7,869.75$ & $\$ 600$ & 84.69 & $\$ 18.435$ \\
\hline 129 & $80 \%$ & $100 \%$ & 77.4 & 137.5 & $10,312.50$ & 774 & 85.80 & 20.00 \\
\hline 129 & $80 \%$ & $80 \%$ & 0 & 182.1 & $13,657.50$ & 0 & 105.80 & \\
\hline
\end{tabular}

The above table is based on a 10 per cent line drop in the first instance and the same line used in the other cases. Cost per $\mathrm{kw}$, generators $=\$ 75$, cost per $\mathrm{kw}$. motors $=\$ 10$. The first two lines show the saving in generator capacity by using synchronous motors. The last two lines show the increased cost of generators required without synchronous motors to load the generators in the first line with synchronous motors.

Mr. Parker says: "Where the synchronous quadrature demand can be made in excess of the lagging quadrature demand from induction motors, it then becomes desirable to put inductance in series with the feeder, thereby overcoming the drop due to the in-phase amperes operating in conjunction with the line 
resistance." By doing this the drop is decreased, but at the expense of a lower power factor, which will increase the $\mathrm{kv}$-a. capacity of the generators fastcr than the decrease in drop decreases it. The idea is that where a transmission problem involves the use of synchronous machines to control power factor it is much better to favor the gencrating station, as it is the most expensive part of the equipment.

M. T. Crawford: Mr. Dwight states that in commercial practise with short lines, constant voltage transmission is worth while mercly on account of the improvement in service. In a system where the average load conditions are found, there are always a number of feeders supplying industrial power and railways in which a voltage variation of 10 per cent is within the limits of good service. For the remaining feeders supplying light and small power, automatic feeder regulators can be installed and operated at a much lower cost than the synchronous condenser installation for constant voltage operation. It might thus appear that where the lines are fairly short and no marked saving can be made by their increased carrying capacity, separate automatic regulation might generally be more economical, especially as it avoids increasing the amount of apparatus and complication of the high-tension system.

Henry W. Peck: An idea which may be of interest occurs to me, viz., that possibly we can use synchronous motor exciting apparatus to greater advantage at the distributing end of some of our lines than at the generating station end. In Schenectady, where we purchase 40-cycle power and transform it to 60-cycle, we have several small machines in the generating station which we practically never use, and as soon as I return home I intend to look up the matter as to whether or not we can use these motorgenerator sets advantageously as synchronous condensers on some of our long feeders.

One line which I have particularly in mind supplies an amusement park about five miles $(8 \mathrm{~km}$.) out of the city, the line being about ten miles $(16 \mathrm{~km}$.) long. When the park is not being run we get reasonably good regulation on the line, but when the park is in operation we have a good many complaints regarding our service. I belicve we could advantageously take some of our synchronous generating equipment and make better use for it at the end of the line. I realize in making this suggestion that the present machine would not be ideal for that service, but when you consider the scrap value of such a machine, which is all that you could get for it, it means the tying up of very little investment for the sake of this regulation. If this idea is not practicable and this plan will not apply I will be glad if some of the designing engineers will tell me why it will not apply.

F. C. Caldwell: What is the comparative effectiveness of synchronous machines, such as synchronous condensers, when running at full load, running at half load, and running light?

F. D. Newbury: I think that Mr. Caldwell's question can be best answered by reference to the familiar right-angle triangle 
of which one side represents the energy load carried by the motor in any particular case; the side at right angles to this, represents the leading wattless $\mathrm{kv}$-a. supplied to the supply line; and the resultant of these two represents the total $\mathrm{kv}$-a. load on the motor. If the energy and wattless loads are equal, (representing the total load by 100 per cent), each will be equal to 71 per cent. Thus, if these two functions were performed by separate motors, the two motors would require a combined capacity of 142 per cent. If the ratio of energy load to the total load were smallersay, 60 per cent- the wattless component would be 80 per cent to load the motor up to 100 per cent. Thus 140 per cent "service" is obtained as compared with 142 per cent in the previous example. It will be found that the maximum service will be obtained from a given motor when the energy and wattless components are equal-in other words, when the energy load is $\mathbf{7 1}$ per cent of the total. This, of course, is the same as 71 per cent power factor.

Burton McCollum: Mr. Dwight points out in a very effective manner some of the advantages that accrue from the use of synchronous condensers in connection with constant voltage transmission, particularly the operating advantages, and he also cites some rather remarkable economies, particularly where he gives some comparative cost data, but I believe that in most cases these economies are largely apparent only.

In the second comparison for the $100-m i l e(160.9-\mathrm{km}$.) transmission line he makes a comparison on a $54,000-\mathrm{kw}$. transmission, and reduces the efficiency of transmission from 95 per cent to 91 per cent, but by so doing he is able to bring about an economy of something like 26 per cent in the initial installation. Now, if we figure the money value of the increased energy loss that results, using the rather liberal line loss factor of 0.3 ., (the ratio of the average square to the maximum square) and taking one half a cent per $\mathrm{kw}$-hr. for the value of the energy, we find it figures out at $\$ 27,500$ a year as the value of the energy loss, which is more than 10 per cent of the saving that results in the line construction.

A similar statement can be made in regard to the first comparison, although the results are somewhat less marked. This statement would of course apply to a steam plant transmission line rather than a water power transmission. In the case of the water power plant the value of the energy lost would be less, but the line loss factor would usually be larger, which would partly offset the lower value of power.

I do not want to detract in any way from the importance of the paper by Mr. Dwight, because I regard it as an important development in engineering, but I feel that the advantages that are to be looked for are for the most part advantages in improved operating conditions rather than in increased economies.

H. B. Dwight: Mr. Parker's paper on the application of synchronous motors in the distribution of power in cities, shows 
that this type of apparatus produces desirable economies and improvements in operating conditions in this class of work. As he points out, the supply company is benefited rather than the customers, and accordingly the latter must be compensated for installing the more expensive synchronous machines. $\mathrm{He}$ suggests making compensation by charging for the kilovoltamperes supplied, thus influencing each customer to operate at all times as closely as possible to 100 per cent power factor.

Although it is evident that compensation must be made to secure the installation of synchronous motors, there are two objections to the above method of charging for electric power, namely, that the kilovolt-amperes are very difficult to meter, and that this method does not secure the best possible benefits from the synchronous motors according to the real needs of the supply company. The benefits may be of two kinds; first, reducing the kv-a. load on the generators. and second, reducing the cost of feeders by improving the voltage regulation. For the first, the synchronous motors should operate as strongly leading as possible at all times, but for reducing the necessary cost of feeders, which is often comparable to the cost of generators and which is also often increased by poor voltage regulation, adjustment of the synchronous motors is necessary. This is well accomplished by automatic regulators, as mentioned in Mr. Parker's paper. The saving in cost of feeders can also be made by installing a high-voltage transformer. Neither of these methods of operating the motors corresponds to keeping the customer's power factor at 100 per cent. It is accordingly better not to charge for the kilovolt-amperes, but to charge for the kilowatts, as usual, and to have a separate provision in the contract giving a bonus to the customer for operation of the motors either according to instructions from the company, or by automatic regulators.

Regarding the paper on constant-voltage transmission, $\mathrm{Mr}$. Newbury, I believe, mentioned that for railway work the frequency of 60 cycles is being used to an increasing extent. This is true where alternating current is used to supply direct current railways, since the 60 -cycle synchronous converter is now becoming more popular. But for single-phase and three-phase railways, the frequency of 25 cycles is used, owing to the characteristics of the motors.

The same speaker asked if allowance had been made for the ten per cent difference in the power factor of the generators in the 200 -mile $(321.8-\mathrm{km}$.) line. The item was not written down in the comparison as it would amount to only about $\$ 20,000$. A more important item is the cost of energy for extra line losses with the constant-voltage system, as mentioned by Mr. McCollum. For a water-power plant, this item is equal to the cost of machinery to supply the extra losses at peak load. At $\$ 50$ perkw. this amounts to about $\$ 200,000$ for the 100 -mile $(160.9 \mathrm{~km}$.) line which $\mathrm{Mr}$. McCollum took up. Against this item, there 
must be taken into account the two other items not put into the table because of their indefiniteness. These are the saving in the cost of land and the value of the improvement in service, and they balance fairly well the cost of power for extra losses. The purpose of the cost comparisons in the paper is to point out that for almost any installation it is worth while figuring up costs to see if synchronous condensers are not profitable.

The curves shown by Mr. Hagood were very interesting and I have just one small matter to bring out regarding them. The capacity of the synchronous condensers was plotted always as a straight line. You will notice in the chart, Fig. 5, of the constant-voltage paper, that the capacity of synchronous condensers required is a curved line, and its curvature puts a theoretical limit on the amount of power which can be sent over a transmission line. In the case considered, of the $200-$ mile $(321.8-\mathrm{km}$.) line, the limit is only ahout 25 per cent more than the amount of power assumed for full load. The curvature of that line is evidently worth figuring up in long distance work. It is a rather peculiar effect that there is this theoretical limit to the power capacity of a transmission line of a certain voltage, which cannot be overcome by synchronous condensers nor anything else.

Lee Hagood: I cannot prove these curves mathematically, but I have tried a number of them and found them all straight lines.

H. B. Dwight: I have no doubt that the points you have plotted, as you say, are correct, and as far as you have gone along the line, it is practically straight. But the indication in plotting a straight line is that unlimited power could be transmitted over the line if enough synchronous motors were added. The limit, however, is struck very soon by this theoretical consideration which will show up if you try to put 50 per cent more power over the transmission line. You would run into the limit with your calculations in the same way.

Lee Hagood: I do not agree with you.

J. C. Lincoln: I inquire of Mr. Newbury what the starting torque is when synchronizing on the three types of rotors shown on page 1514. The curve is interesting, and it appears that the starting torque of the rotor with the brass damper windings is at rather high resistance, which is much greater at any particular voltage than in the case of the starting torque at low resistance, and my question is, which is the type of rotor that will come in synchronism with the least amount of current? Is it the brass rotor or the low-resistance copper rotor?

F. D. Newbury: To answer Mr. Lincoln's question first; there are two entirely distinct actions to be considered-two entirely different sets of characteristics. The copper damper winding which shows the lowest torque at starting will of course have the lowest torque as long as the motor is operating as an induction motor. The torque at which a given motor will pull into synchronism depends on the torque that results in a certain 
slip. There is a limiting slip, that may be one per cent or two per cent, beyond which the motor is incapable of pulling over from the highest induction motor speed into the true synchronous speed. Therefore the torque, that a given motor will pull in, will depend on the torque that can be pulled by the motor with a given slip. Therefore, the motor with the lowest resistance damper winding will carry the most load with this limiting slip, and consequently will pull into synchronism with the largest load. On the other hand the high resistance winding will develop the largest torque at the lowest speeds as in any induction motor.

J. C. Lincoln: If there was contained in the paper a complete speed-torque curve, would the torque of the lower resistance copper-wound rotor be greater or less at speeds just under synchronism than the torque of the higher resistance brass-wound rotor? It is very evident from the curve shown in Fig. 9 that at low speeds the brass-wound rotors have a very much higher torque than the low-resistance copper-wound rotors. It would seem to me that, at the higher speeds, just under synchronism, the lower resistance copper-wound rotor would have a higher torque than the higher resistance brass-wound rotor, and therefore that a synchronous motor provided with a lower resistance copper-wound rotor would pull into synchronism a larger load than the high resistance brass-wound rotor. I would like to ask the author of the paper if that is the case.

F. D. Newbury: The torque of the low-resistance rotor would be greatest at the highest speed at which the motor operates as an induction motor and will pull into synchronous speed.

J. C. Lincoln: That would amount to the same thing.

F. D. Newbury: Mr. Williamson spoke of the paper on the synchronous motor which was presented at the Pittsburgh meeting of the Institute last year. The admirable paper by $\mathrm{Mr}$. Fechheimer was the starting-point of my own paper, since at that meeting the discussion was not at all favorable to starting with the field circuit closed. It may not indicate any change in the opinion of the members present, but simply indicate a change in audience, that the sentiment expressed at this meeting has been in the opposite direction.

As Mr. Williamson pointed out, I think the tests show that two starting voltages are not necessary, but I would qualify that in this way - that they are not necessary, provided proper adjustments are made, but proper adjustments always mean careful and skilful attention, so that the two starting taps are used and are justified for the larger motors, where the consequences of wrong operation would be quite serious.

Mr. Hobart has regretted the lack of attention that has been given to the wound-rotor distributed type of synchronous motor. I think that it is more a lack of results than lack of attention, and the reason for the lack of results is more fundamental than a difference of engineering department organization as Mr. Hobart 
suggested. The real reason is brought out by the difference in the magnetizing current required by a well-designed induction motor and a well-designed synchronous motor. In an induction motor the magnetizing current is roughly 30 to 40 per cent of the armature current. In the synchronous motor the magnetizingr ampere-turns should be at least one and a half to two times the armature ampere-turns. In order to obtain the necessary exciting ampere-turns on a round rotor synchronous motor a much larger rotor is required than for the salient pole type of synchronous motor or the round rotor type of induction motor. There is a good engineering reason, therefore, for the practically exclusive use of the salient pole type. The same conclusion is reached by a comparison of the weights and costs of salient pole and round rotor types of alternators. I think it is well known that the round rotor type of alternator ordinarily used for turbogenerators means a larger machine and a more expensive machine than the salient pole type and the round rotor type is used because it is the only type sufficiently strong mechanically. The same point was well borne out by comparisons recently made on some 10,000-kilovolt-ampere, 600 -rev per min. waterwheel generators, where the cost of the salient pole type was found to be approximately 50 per cent less than the round rotor type.

M. O. Dell Plain: I believe that the possible advantage to be gained by the average central station through a general use of synchronous motors instead of induction motors on its lines is largely offset by the greatly increased number of motor trouble complaints.

The advantage to be gained by the consumer is a very material one in cases where the central station penalizes a low power factor. This advantage, however, is also offset if the current charge is based directly on the demand. In such cases the present lack of a suitable demand meter results in considering the highest phase $\mathrm{kv}-\mathrm{a}$. reading as being the actual demand, and an unbalanced load being the usual condition, the synchronous polyphase load does not produce its fullest effect in lowering the actual charge.

The development of a reliable and inexpensive kilovolt-ampere demand meter would probably eliminate this objection.

Henry W. Peck: I have made a memorandum of two or three points which I will answer. The quality of the service is oftentimes more important than a very slight advantage in maintaining unity power factor at the station. It is not for the sake of the power factor primarily, that Mr. Parker suggests the use of synchronous condensers, but to maintain the service which we are giving to our customers.

Another suggestion was made that the synchronous condenser was in competition with the high-tension transformer. An operating man does not like to see his system separated into different voltages, 2300 volts on one part, 6600 volts on another part, and 13,000 volts on another part. From the opera- 
ting point of view it is much simpler to have the synchronous condenser than to step up certain portions of the line and have a great variety of transformers which you must carry in stock so as to be able to supply your customers with these transformers when they want them.

Referring to Mr. Dell Plain's remarks, it is manifestly impossible to put a synchronous motor in every and any installation, regardless of the character of the plant and the man who is running it. In the case cited by Mr. Parker where they use the synchronous motors for pumping, refrigerating plants and similar purposes, they have operating men who are certainly of as high a class as any men we have in our own stations and who can be trained to operate the synchronous motors satisfactorily.

We must consider the economy of such an installation from the point of view of both the customer and the company. The customer must decide if the saving, due to the lower rate for power, is sufficient to warrant him in installing these appliances in his power plant, granting that they are not quite as simple and convenient as the induction motor. The company must decide if the saving and improved service incident to the installation of these appliances are worth the expense represented by the decreased rate for power and by the assumption of such part of the first cost of the machine as is represented by the excess capacity required to handle the wattless load.

As regards metering the kilovolt-amperes, I know that it has been done in one installation which was put in under Mr. Parker's direction, using two meters, a graphic voltmeter and a graphic ammeter. The installation in which this meter was placed was of 600-h.p. capacity, and the cost of these meters, while prohibitive on smaller installations, was by no means prohibitive for one of such large size. If the phase voltages were perfectly balanced there would be no difference in the current in the different legs. Measurements were taken at this installation and it was found that the difference in voltage and current in the different legs was negligible.

N. E. Funk: I did not mean to leave the impression that poor service was to be furnished so that the power station might enjoy the benefits of a high power factor, by any means. What I meant to convey was, that it was the best policy to attempt to get unity power factor rather than leading power factor, which is as bad in so far as generator capacity is concerned as a lagging power factor. In following out this manner of design it is not necessary for the voltage at the receiving end of the line to vary any more than if the voltage were the same at both ends. There are various means of correcting voltage besides that of synchronous condensers, and if it is not possible to favor the generating station and get the proper voltage at the receiver this receiver voltage may be corrected by, say, induction regulators, and the synchronous motors used to annul the lagging component of the load. The thing I had in mind most particularly was the 
fact that it was better policy, on account of favoring the generating station and apparatus, which is the most expensive part of the system, to strive toward obtaining unity power factor on the generating station rather than calculating the line for a given voltage at the receiving end and allowing the power factor at the generating station to come what it may.

C. P. Steinmetz: The two papers on synchronous motors are very interesting to me, as they give much additional information regarding the usefulness of the synchronous motor as an element of the electrical system, particularly Mr. Newbury's paper with regard to the starting characteristics of the synchronous motor. Synchronous motors, synchronous converters, and synchronous condensers have now been used extensively for over 20 years, and their use is very rapidly increasing. Most of these machines are self-starting, starting from rest with their own power, but still I believe there are a few engincers who doubt the self-starting characteristics of the synchronous motor and consider this as the main disadvantage of the synchronous motor.

The fact is, as brought out by these papers, that the modern synchronous motor, and also its prototypes, are very well able to start from rest and run up to speed and carry considerable load up to speed. They, indeed, take a large current in starting and during acceleration, about as much as the large highly efficient induction motors. The induction motor has never been questioned as to jts ability in starting; but the synchronous motor is fully as well self-starting, and sometimes it takes more current and sometimes less current than the squirrel-cage induction motor, as, indeed, it is an induction motor. It differs in these starting characteristics, from the standpoint of the wellknown squirrel-cage induction motor of large size, only in the proportioning of the parts. The starting characteristics of the induction motors have been limited by the proportioning of the parts required for getting efficient running, mainly for the purpose of getting high efficiency, high power factor, or low exciting current.

These limitations are not questioned in the induction motor characteristics of the synchronous motor, because the synchronous motor is not expected to operate at speed as an induction motor. Therefore, whatever power factor and efficiency it might have when running at speed as induction motor is entirely immaterial, and therefore in proportioning the induction motor parts of the synchronous motor we are more unrestricted, in choosing those proportions which are capable of giving good starting characteristics, than we are in the large induction motor. That means in many cases it is possible to give to the synchronous motor better starting characteristics than to a large squirrelcage induction motor. I pointed out some of these things in a previous discussion, for instance, that in the synchronous motor we may have, considering it as an induction motor, an exciting 
current of 100 per cent or more without its having any detrimental effect. In the induction motor. obviously such an exciting current would make it commercially inoperative; the reason being, at that time, under the conditions where the synchronous motor acts as an induction motor in starting, the energy current for acceleration is so large and the impedance current is so large that the exciting current does not cut any figures. It is negligible, no matter how much it would be in percentage compared with full load current.

The main differences in the proportioning of the induction motor part of the synchronous motor compared with the induction motor are three. First, the synchronous motor does not have uniform magnetic reluctance in all directions of the rotor, it is minimum in the direction of the field poles, and maximum at right angles thereto while the induction motor has uniform reluctance all around. This is a disadvantage in regard to the starting of the synchronous motor as an induction motor, since it tends to a lack of uniformity of the torque with the relative position, and thereby also tends to low torque points, that is to a tendency of sticking, as it is called, at intermediate speeds. more particularly at half synchronism. Second, the synchronous motor has a very large air gap compared to the air gap used in the induction motor. The induction motor, to get good power factor, low exciting current, must have as small air gap as mechanical construction permits. In the case of the synchronous motor the power factor and the running on light current do not depend on the length of the air gap. Therefore the air gap, in the case of the synchronous motor, is chosen in accordance with very conservative mechanical and other considerations. The large air gap has an advantage in starting, in so far as it tends to give a uniformity of torque. Third, the secondary winding of the synchronous motor, compared with that of the induction motor, is of much higher resistance, which again is an advantage in starting, so, you see, of the three main characteristic differences in the proportioning of the induction motor part of the synchronous motor, one is against but the other two are in favor of high starting torque and the result is that the synchronous motor really starts better than a large high efficiency squirrel-cage induction motor.

The oscillograms shown in Mr. Newbury's paper are extremely interesting in giving the starting characteristics, but from these oscillograms you can see there are many other things which the limitation of space did not allow Mr. Newbury to show. If you look at them you see this more particularly, in the case of the oscillograms of a current, the amplitude of the current, the periodic rise and fall. You see the meaning of that-it is due to the varying magnetic reluctance with the position; maximum current corresponds to maximum reluctance, minimum current to minimum reluctance. Hence the distance from current maximum to current maximum corresponds to the dis- 
tance moved by the rotor from one maximum reluctance point to another maximum reluctance point, which means the distance of half a field pole or multiples thereof, or the slip of half a field pole or multiples thereof. That means the space moved through but the frequency of the oscillograms gives the time, and therefore you see from these oscillograms that you can get, from the distance moved by the rotor and the time of motion, the speedtime curve during acceleration, and from the speed-time curve you get the acceleration-time curve, and therefore since acceleration gives you the torque, relatively, or when considering the momentum of the moving mass, then absolutely, you get the torque-speed curve. That means a variation of the torque of the machine from standstill up to synchronism. All the characteristic curves of motion you get from these oscillograms, curves which in the induction motor are difficult to get, because in the induction motor the speed range near maximum torque, is unstable, and characteristics of that range can be derived mainly by connecting the motor with a generator which feeds a direct current motor connected to constant speed shafting and varying the field excitation of the motor which checks the output. This is well known and has many times been described, and in this way you can hold the induction motor at any point of speed, stable or unstable, above or below synchronism, and you can get the complete torque characteristics. The oscillograms of the synchronous motor permit you to arrive at a very definite understanding of the speed-torque characteristics, which in the induction motor you might get, possibly, an exploring winding on the squirrel-cage.

Looking at these oscillograms, you see a number of characteristics which are incidentally mentioned. If you take curve Fig. 2, at the end of the first oscillogram, you see a number of waves with a high and low amplitude alternating for a considerable number of periods there. Apparently the speed was practically constant, which meant a low torque point there, where the motor accelerated slowly, because after a considerable number of cycles there was no acceleration or little acceleration. That apparently corresponds to one-quarter synchronous speed, and later on at about two-thirds the distance of the second curve from the bottom of the page, there was a very large number of cycles where the amplitude is constant, where the machine moved from maximum reluctance point to maximum reluctance point, during one cycle or during half a cycle. During half a cycle it progressed half a field pole. That apparently is half synchronous speed where it tends to drop off a little. The next curve is still exaggerated, but much less prominent at the threequarter synchronous point, so that if you would construct from the oscillogram the speed-torque characteristic, you would probably be required to introduce a considerable drop in the torque at half synchronism, a moderate drop of torque at onequarter synchronism, and a further moderate drop of torque at 
three-quarters synchronism. This is at the low voltage starting. At higher voltage starting that phenomenon is not so marked, but these oscillograms allow you to study the acceleration curve of the synchronous motor much more closely and control it much better than in the case of the induction motors, where it is more difficult to determine all these characteristics of intermediate speed. We thus see that, as an engineering problem, when it is necessary to provide high efficiency synchronous motors with good starting characteristics what we have really is a much more simple problem than in the case of the high efficiency induction motor. and in my opinion the large synchronous motor is really one of the most important, and most useful elements of the electric system, more so than the induction motor, because instead of spoiling the power factor it may be made to improve the power factor, and instead of interfering with the regulation, making the voltage vary more with the change of load, it controls, or permits the control of the voltage; or acts automatically without any control, by establishing a fixed voltage point due to its excitation. The synchronous motor tends to hold the voltage more nearly constant than the non-inductive load. Many engineers do not yet realize the usefulness and value of a synchronous machine as an element in the electrical system, and therefore I very much appreciate these papers, since they give additional information and undoubtedly will tend to give the synchronous motor a still wider application than it has today. The synchronous motor will naturally include the synchronous converter and the synchronous condenser.

W. L. Merrill: I desire to ask Dr. Steinmetz a question in connection with his discussion on synchronous motors, and that is, why he compared the large synchronous condensers or synchronous motors with squirrel-cage induction motors. It has been my experience in such applications where the question has arisen as to whether synchronous motors or induction motors should be used the squirrel cage motor would not even be considered; and it has been the custom always to supply wound rotor collector-ring type of motors in the majority of cases where practically any starting requirements were to be met. In some cases, however, where synchronous motors have been installed to do the work that is successfully being done by wound rotor motors, the operation of the synchronous motors compares favorably with the operation of a fuse after it is blown. I see no reason for comparing the synchronous motor with the squirrel cage induction motor for ordinary industrial applications.

R. B. Williamson: In regard to the point brought up by Mr. Newbury about the wound-rotor type of motor, my idea was not to recommend that type of motor in preference to the salient pole type. The experiment was tried simply to find out if that sort of motor could be started up equally well. Motors of this type might occasionally be used for high speed work. For ordinary service at moderate speeds they would have no material advantage and would be larger for a given output. 
F. D. Newbury: I wish to thank Dr. Steinmetz for his contribution to the discussion, particularly, because his discussion brought out a number of points I hoped would be brought out; and I am free to confess that they were not included in the paper for other reasons than lack of space and time, as Dr. Steinmetz was kind enough to suggest.

There is one point in particular I have not been able to understand myself; possibly Dr. Steinmetz can explain it either now or after he has studied the matter a little. Figs. 28 and 29 show exactly the same conditions but there is a very marked difference in the amplitude of the armature current and field current changes.

C. P. Steinmetz: I wish to think the matter over a little more and cannot give an answer now, but in regard to the former question, as to why I compared the synchronous motor with the squirrel-cage induction motor, the reason was that, when the synchronous motor starts, it starts as a squirrel-cage induction motor, since it is provided with a squirrel-cage, so we would naturally compare that with the squirrel-cage induction motor.

We all realize that there are very many motor applications where we need frequent starting at heavy torque and where we: therefore use the collector-ring induction motor. These applications naturally would not, as a rule, be met by the synchronous motor but in the majority of cases the squirrel-cage induction motor is used and therefore I compared that motor with the synchronous motor. It does not mean that we can use a synchronous motor in every place. The induction motor with collector rings and rheostat armature control has its legitimate and very important field. We may say that since the synchronous motor starts as an induction motor instead of providing a squirrel-cage, a regular winding could be used with a rheostat and improve the starting of the synchronous motor and such was the point I made.

I remember the first big synchronous motor with which I had anything to do, that was in 1893, somewhere on the Pacific coast. The motor is still running. It had a three-phase pole face winding, each winding brought out to a switch, in which a rheostat was connected for starting, but that has never been done since, because there was no need for this complication; and in all the conditions where the synchronous motor was used it was considered ail right to start as a high-resistance squirrel-cage motor. That might possibly be done in the case of the synchronous motor by giving it collector rings and the wire-wound induction motor winding. The objection to that is it means a winding which is used only in starting not in running, and that is a complication. If the winding is simple, as in the case of the squirrel-cage motor, which incidentally acts as an amortisseur winding - a damper winding when running at synchronism, -then it is favorable, but it is hardly justifiable in most cases, to go to the complication of an external rheostat, but rather to 
use an induction motor with collector rings and rheostat, except in those cases, which may occur, where the synchronous motor is decidedly preferable. I do not recall any cases like this.

J. C. Lincoln: I would like to ask what is Mr. Newbury's experience with reference to the call for high starting torque at low speeds and high starting torque at near synchronous speeds. It happens my experience has been only where we had trouble when it was due to the fact that we had to have pretty high speeds near synchronism, but judging from the paper, and from the curves which are very instructive, I would infer Mr. Newbury's experience has been in cases where high torque was required in starting, and I ask what his experience is as to the ordinary requirements of starting torque, whether a high starting torque is required at starting or near synchronous speed?

F. D. Newbury: Whether the required starting torque is greatest at standstill or synchronous speed depends on the application. The majority of synchronous motors is used in motor generator sets where the largest torque is required at standstill. This may be considerable, as much as 50 per cent, in some cases, of full load torque. In the case of pumps and fans and air compressors, the highest torque is usually required near synchronous speed. In the case of fans it is very hard to shut off the air supply sufficiently so that the torque at full speed is not very near the full load torque of the motor. In the case of pumps where a by-pass can be used, the torque at synchronous speed is considerably reduced. In the case of air compressors, the bulk of the trouble has been at pull-in, and I imagine the absence of trouble in many cases has been due to the fact that the motor was pulled in on full voltage and not starting voltage. Probably the bulk of the synchronous motors have been used f or motor generators sets, where the starting torque is the greatest, so that quantitatively the bulk of the trouble has been at standstill.

J. C. Lincoln: With a motor-generator set, would you use a low-resistance winding on the motor?

F. D. Newbury: Not necessarily. Many and perhaps the majority are now built with the brass or high-resistance squirrelcage windings, illustrating the point Mr. Hobart and Dr. Steinmetz made, that it is possible to obtain the good starting performance of the high resistance secondary with the synchronous motor while it is not possible with the squirrel-cage induction motor. With steam- or water-driven generators now generally used there is little necessity for low-resistance amortisseur,windings for prevention of hunting.

H. H. Dewey: Mr. Newbury implied that in the case of large, slow-speed synchronous motors, having a large number of poles, it is a difficult matter to obtain high torque during synchronism. Do I understand that it is harder to obtain it with a machine of this kind than with a high-speed machine having a smaller number of poles, and if so, to what does he attribute the difference? 
F. D. Newbury: It is decidedly more difficult to get high starting torque at pull-in, as expressed in percentage of motor output, with the larger number of poles, and in the case of slow motors for air compressors the figure which has been more or less standardized by the compressor manufacturer's requirements, and also by tests, is about 15 per cent; that is, the motors will develop 15 per cent of their normal torque at synchronous speed. I have one installation in mind where they would just pull in, and the tests on the test floor show just about 15 per cent pull in torque. With slow-speed, two, four, and sixpole motors, used for fans, it is not difficult to pull in at practically full load torque, if you disregard the starting torque and current. The reason for this difference is rather intimately connected with the proportions of the two machines.

H. M. Hobart: For a long time salient stator poles were used for very high speed generators, but now I think there is a fairly universal agreement that the windings should be distributed, although it is only comparatively recently that there was any general agreement on that point. Previously the salient pole was strongly advocated for even very high speeds. I feel that there should be a closer analysis of the differences in the construction and of the respective fields of usefulness of synchronous motors and induction motors. If the synchronous motor is to be developed on progressive lines the work must be entrusted to those who are accustomed to induction motor design.

J. H. Wilson: The question has been brought up of the pulling-in effect with a high resistance motor. I may mention two cases I had recently to do with, where a 2400 -h.p. synchronous motor was connected to some grinding stones for grinding pulp. The grinder in question was of a comparatively new type, where the wood is piled in the hopper, twelve cords of wood pressing on the stones at all times. This particular motor had a high resistance it had a squirrel-cage winding. I have no way of finding out what the pull-in torque was, but it must have been considerable, because there was always a large amount of wood pressing down on the stone, each stone taking about 1200 h.p. That motor would start up on $1 \frac{3}{4}$ to 2 per cent full load current on half the line voltage, and seemed to pull into step without trouble, so that the high resistance winding at or near synchronism must have given fairly high torque.

C. P. Steinmetz: Regarding the pull-in torque, I wish $t_{\text {' }}$ draw attention to the necessity of some further study of this matter. The phenomenon in the synchronous motor pulling in to synchronism is not fully realized by all engineers. It is really not so much a question of the load which is to be pulled in but a question of momentum. A synchronous motor may have difficulty in pulling into synchronism while accelerating without any load, while it may pull in nicely without any difficulty at full load, because when pulling in it means it has to jump from the slip given by the induction motor into synchronism, and in 
that very short period it has to accelerate the momentum. The acceleration of the momentum is usually very much poorer than the actual load, so that you will find, when studying the pulling in of a synchronous motor, especially a high-speed motor connected to high-momentum apparatus, that the question of load or low load makes practically no difference, or very little difference. What we have to consider in the pulling-in characteristic of the synchronous motor is the momentum which has to be pulled into step, much more than the actual drag or torque.

F. D. Newbury: I do not wish to lcave the discussion of round type versus salient type motors where it stands. There is not as much difference between Mr. Williamson and myself as might appear. I still hold to the point that it is a question of cost, and that is a hard question to overcome unless you can overcome it in the direction of a reduction of cost. I do not see how, from theoretical considerations, you can do that. Maybe I am mistaken, but I cannot see it.

There are others, notably Mr. Foster, who have had experience along these lines, and I would like to know from him and others, whether their experience has been the same as mine; that the salient pole type for a given output can be built more cheaply than the round rotor type?

I am entirely in agreement with what Mr. Williamson said in regard to the performance of the round rotor type. There is nothing against its performance; in fact, it has very decided advantages, as Mr. Williamson pointed out; there is uniformity of reluctance so that there is a uniformity of torque in the rotor; the starting performance of the phase-wound induction motor can be obtained by inserting resistance in the external exciting circuit; other decided advantages have led designers to investigate it thoroughly. If my conclusions are wrong, I would be glad to be corrected.

Wm. J. Foster: My experience agrees entirely with $\mathrm{Mr}$. Newbury. That matter has been investigated in a number of cases during my experience of 20 years or more. I think the first synchronous motor I had anything to do with was built with pole faces 85 or 90 per cent of the pole arc, as against the ordinary 65 per cent of the generator. Much of the investigation made along that line, with regard to the design of the synchronous motor, is based on using stock parts of induction motors, since we have the benefit of the cheaper production, due to stock parts, and can easily make, the nesessary modifications in the rotor, with the increased air gap, etc. It has been my experience that we have never been able to work out that type of motor in competition with the salient pole in any size in which synchronous motors are called for. In very small motors, it is often a profitable thing, because there is not demand enough to warrant the development of an entire new salient pole machine. Hence the synchronous motor can be best built from standard induction motor parts in very small sizes. 
As to the matter of the characteristics, I am sorry I have not exact data on the subject, but as far as my experience goes it has been in favor of the round rotor, that is, in returns that one gets for the input.

H. M. Hobart: People are usually willing to pay more for a good thing than for a bad thing, if only they can get the gcod thing.

W. J. Foster: I want to know in what respect it is a good thing as compared with the present motor. Why do you call one good and the other bad?

H. M. Hobart: I call it good because it starts with high torque and runs rapidly up to synchronism with good torque all the way through. These are not characteristics of syr1chronous motors as at present designed.

Wm. J. Foster: I have built and operated a number of motors of the wound rotor type, but I cannot agree with that statement. It is a question of how to adjust things with relation to the torque, and that is a serious drawback in the synchronous motor. It is right there where investigation has been going on quite actively in the last two or three years as to how to increase the torque.

R. B. Williamson: It seems to me the only reason for building synchronous motors with round rotors is the same reason for which we build generators with round rotors. It is a question of speed. To design a motor for, say, $3600 \mathrm{rev}$. per min., we would have to use a mechanical construction the same as for a turbogenerator; but for ordinary speeds where we would use a salient pole construction for a generator I should say by all means to use it for the synchronous motor. I do not think there are any great differences in the characteristics; the only thing I had in mind was the question of overcoming the mechanical difficulties at high speed.

W. L. Merrill: The principal point I wanted to bring out by asking Dr. Steinmetz the question I did is that the author of one of the papers appeared to be advocating loading up the central station lines with synchronous motors to the value of 40 or 60 per cent of their total load. My experience in industrial work is that possibly one or two per cent of the industrial applications of motors, with the present type of synchronous motor which we have, could be handled by synchronous motors, and I was afraid from the glowing comparison which Dr. Steinmetz made of the synchronous motor and induction motor that the impression might be gained that they were interchangeable, when as a matter of fact in the sizes which he was discussing no one would consider the question of a squirrel-cage motor any way. If we could get large synchronous motors, involving the characteristics of the form wound induction motors, it would not only be possible, but probable, that the central stations could go to 40 per cent of the total loads with synchronous apparatus. 
Wm. J. Foster: I wish to say iti connection with the point brought up by $\mathrm{Mr}$. Hobart that if you put in an external resistance with a definite wound rotor, and make use of external resistances, you get excellent results, as far as starting torque goes. You can then cut out the external resistance and switch the excitation on two phases of the rotor winding, leaving the third phase idle, or use one phase against the other two for excitation.

H. M. Hobart: In my first remarks I said there were various ways of improving the motors which were quite available and valuable, but that no one wanted to use them, but I did not go into the question of what those ways were. They related to this question $n$ f getting a high torque not only at the moment of starting, but a high torque right straight through into synchronism. $I$ did not feel that it devolved on me to go into the details of these methods on this occasion, since I have already published descriptions* of them. It is an interesting field to which little attention has been given. These methods will be widely used in the future. At present they are opposed in accordance with those general principles always acting when new ideas of value are first brought to attention.

C. P. Steinmetz: I do not think I am prepared to discuss off-hand the last subject which was brought up. We all realize what we have in the synchronous motor is the induction motor start, and also in the starting of the squirrel-cage, as squirrelcage that is, high resistance in starting and decreasing resistance to a very low resistance at running, and that decrease should be as simple as possible.

In regard to the difference between the definite pole rotor and the uniform reluctance rotor, the main differences in my mind are that the definite pole rotor gives a less uniform starting torque, and if in starting we must consider the momentum torque, the definite pole rotor is inferior in starting, other things being the same, than is the uniform reluctance rotor. Furthermore, the definite pole rotor shows a drop in torque at fractions of synchronism, a certa:n amount at hali synchronism, and less at quarter synchronism, more than the uniform reluctance rotor, which latter very often does not show a drop in the torque curve at all. On the other hand, the definite pole rotor drops into step easier, because it has that additional torque, the tendency of the magnetic lock, therefore in dropping into synchronism the definite pole rotor has the advantage.

At the moment of starting, the synchronous motor of today has ample torque to start any load which it will carry. However, the stopping off at half speed has been a very decided disadvantage in former times in the synchronous motor, but with the introduction of the fairly well distributed squirrel-cage winding, even with the winding local only through a wide field pole,

*See pp. 202 to 212 of "Design of Polyphase Generators and Motors", by H. M. Hobart, 
that difficulty has practically vanished, so that as it stands today, on the average there is very little to choose between the definite pole rotor, and the uniform reluctance rotor. You cannot say they are exactly alike, the one is better in pulling in and the other is better in acceleration, but after all, that is a question of the nature of the load, and also a question as to how much the one advantage or the other is worth under the greater cost of the construction, or whether it is not worth anything at all. It is really like most engineering problems, an economic question between the engineering design and the requirements of service, and the cost of the apparatus; but in the last five or ten years the advantage in development has been largely in improving the starting condition and the fraction synchronous condition, that is, reducing and eliminating the disadvantage of the definite pole construction, so that today the definite pole construction really has practically no disadvantage as a synchronous motor over the uniform reluctance type. Today indeed in the synchronous motor, that field in which there is the least known or available in the literature, are the phenomena of pulling into step, and as you have heard from Mr. Foster a large amount of investigating work is being carried on in this direction, and I hope Mr. Foster will be able, at some of the future meetings, to give us some additional information of the phenomena occurring in the synchronous motor in that range of speed where it is not an induction motor any more, and where it is not yet a synchronous motor.

C. J. Fechheimer (by letter): The many oscillograms in Mr. Newbury's paper convey to our minds an unusually clear picture of the phenomena from standstill to synchronism, of the transients produced by the varying reluctance of the magnetic circuit due to the projecting poles, and those caused by temporary changes when the connections are altered. Inasmuch as the physical conception of a phenomenon frequently is of more importance than the mathematical, especially to the engineer or student who does not design the apparatus, the graphical oscillograph records are of great value.

Mr. Newbury states: "These facts show the desirability of starting synchronous motors with the field circuit closed (and so eliminating the high voltage from the field winding and the switchboard), except in special cases where unusually high initial starting torque is required. For such applications a high resistance damper winding is necessary, the benefits of which in producing torque would be largely nullified by the closed field of circuit. In such special applications, however, care must be taken to insure that the insulation of the entire field circuit will withstand the resulting voltage." This statement applies to motors with rotors equipped with squirrel cage windings and laminated poles. Mr. Newbury has not commented at all on synchronous motors with solid poles. We wish to call attention to the very desirable effects which can be produced 
with solid pole rotors in which eddy currents are crowded into thin shells toward the surfaces, (the well-known skin effect phenomenon), whereby the starting torque is increased, whereas the number of inter-linkages of flux with the field turns is reduced, with the result that the induced voltage in the field coils is lowered.

We give below some data from actual solid pole machines which were available for the tests. From them it will be seen that the induced voltage with solid poles is small as compared with that obtained with laminated poles in which the squirrel cage construction is embodied. Instances of these latter are cited in Mr. Newbury's paper. We have taken as a basis of comparison the induced voltage with a torque of 30 per cent of normal full load torque, this value being as large as is usually demanded of synchronous motors at starting.

\begin{tabular}{|c|c|c|c|}
\hline \multicolumn{2}{|r|}{ Rating } & $\begin{array}{l}\text { D-C. excit- } \\
\text { ing voltage }\end{array}$ & $\begin{array}{l}\text { Rotor volt- } \\
\text { age for } 30 \% \\
\text { torque }\end{array}$ \\
\hline $2000-\mathrm{kv}-\mathrm{a}$ & 11,000 -volt three-phase 50 -cycle 600 rev. per min. & 125 & 1690 \\
\hline $180-\mathrm{kv}-\mathrm{a}$ & 2300 -volt three-phase 60 -cycle 150 rev. per min. & $1: 5$ & 1790 \\
\hline 350-h. p. & 2300 -volt three-phase 60 -cycle 257 rev. per min. & 250 & 2610 \\
\hline 50-kv-a. & 240 -volt three-phase 60 -cycle 1200 rev. per min. & 125 & 1440 \\
\hline $100-\mathrm{kv}-\mathrm{a}$ & 240-volt two-phase 60 -cycle 257 rev. per min. & 125 & 1230 \\
\hline $150-\mathrm{kv}-\mathrm{a}$. & 275 -volt three-phase 60 -cycle 900 rev. per min. & 125 & 427 \\
\hline
\end{tabular}

We do not favor short-circuiting of the field coils at starting, since, for a given starting torque, not only is the line current increased thereby, but there is a possibility of the rotor refusing to accelerate beyond half speed unless the field circuit is opened. As stated by Mr. Newbury, and also in my reply to the discussion of my paper on Self-Starting Synchronous Molors*, the rheostat resistance is entirely inadequate in assisting toward the reduction of line current for a given torque at the instant of starting. Motors with solid rotors have been built sucressfully for a number of years, and so far as we are aware, all of them are started with the field circuit open, the induced voltage in no case being prohibitive, no disastrous results having come to our attention as a result of the induced voltage.

It is interesting to note that with the solid pole construction, the torque is not proportional to the second power of the voltage, as is generally assumed, but to a slightly higher power, about 2.1 to 2.5 Similarly, the other quantities vary in a different manner than generally assumed. For example, in a certain $100-\mathrm{kv}-\mathrm{a}$. solid rotor synchronous motor, the following relations were found by plotting results on logarithmic cross-section paper:

1. Torque varied as 2.5 power of voltage.

2. Torque varied as 1.73 power of current.

3. Current varied as 1.38 power of voltage.

*Trans. A. I. E. E., Vol. XXXI, 1912, p. 529. 
4. Power input varied as 2.53 power of voltage.

5. Torque varied as 1.05 power of kilovolt-ampere input. input.

6. Kilowatt input varied as $\mathbf{1 . 0 5}$ power of kilovolt-ampere

7. Torque varied as the first power of kilowatt input to rotor.

A comparison of the above relations will reveal their consistency.

We believe that the departures indicated above from what would seem to be the most rational laws are due chiefly to the increased crowding of eddy currents into the shells of the rotor surfaces as the current is increased; thus the reactance of the eddy current paths is reduced, the current is proportionately increased, the power factor is slightly increased, etc. There are advantages in these relations, among them being that they result in a not inconsiderable gain in torque for a given increment of voltage, especially when the demand for such torque is greater than was first anticipated.

At first thought it may appear that the starting characteristics with the solid construction are predicted only with great difficulty due to the uncertainty of the laws which eddy currents follow. We would therefore call attention to the method given in my paper on this subject, and state at this time that we have been using this method for about three years with great success. We have recently modified the method so as to include exponents other than generally assumed, such as indicated above. With these modifications our method is substantially the same as previously described. In fact we believe that greater accuracy in the prediction of starting characteristics can be secured with the solid construction than with the laminated squirrel cage construction, there being less uncertainties in the former than in the latter.

The above is not intended to be more than a partial comparison of solid and laminated pole squirrel cage rotors.

It is now generally conceded, that insofar as the current taken when breaking loose from rest is concerned, the air gap should not be made smaller than would be best suited for the motor after it comes into synchronism and is excited in the ordinary manner. I wish to call attention, however, to my statement given in reply to the discussion of my paper previously referred to: "When operating at synchronous speed without direct-current excitation the current drawn from the line depends almost wholly upon the magnetomotive force required to force the flux across the air gap." From this point of view it will be seen that the effect of the air gap upon line current may be of considerable importance.

In Fig. 7, Mr. Newbury shows that the current after synchronism is less than at any time during acceleration. This would imply that the air gap is small, since as stated above, the air gap reluctance plays the chief part in the current taken after the machine locks into synchronism with no direct-current 
excitation. In the various speed-torque curves shown in my paper, the current after locking into synchronism is somewhat greater than just before synchronism is reached. If a synchronous motor is designed to give double torque for pull out and is intended for unity power factor operation, the air gap will generally be of sufficient length to cause the current after locking into step to be greater than at about 95 per cent of synchronism. On the other hand, if the motor is designed with a small air gap and is intended to operate with leading power factor for balancing some of the lagging current in a system, the air gap may be so short that the current flowing when the motor is in synchronism without any direct current excitation is less than at any point during acceleration.

Mr. Newbury starts his synchronous motor on fractional voltage and excites the fields before throwing over to full voltage. He states: "The armature circuit is momentarily opened by throwing from the low voltage to the high voltage and current drops to zero during this interval." If the circuit is to be opened and then closed, his method might be a desirable one in cases where stored energy in the rotating parts is high, frictional torque comparatively small and the mechanical angle between adjacent poles comparatively large, such as would be the case, for example, with synchronous motor-generator sets. On the other hand, were the synchronous motor to drive a reciprocating air compressor, the motor operating at a small angular velocity, the frictional resistance being rather high, the mechanical angle between poles small and the stored energy small, the rotor may change its phase position appreciably during this transitional stage. When full voltage is then applied, there is a possibility of setting up rather high mechanical forces and of causing a momentary large current rush. Hence, we may conceive of trouble ensuing in cases of this kind. It may then be best to throw on full voltage before applying direct-current excitation. If the circuit is kept closed during the transition from fractional to full voltage, we believe it best in all cases to excite the fields on fractional voltage, so as to reduce to a minimum the current which would flow after full voltage is applied.

It is usually undesirable to apply as much as unity power factor exciting current in order to cause the motor to lock into synchronism provided synchronous speed cannot be obtained without the application of such current. In Figs. 11, 12 and 13 and accompanying description in my paper referred to above, it is shown that there is a critical value of excitation for each speed which will give maximum torque, beyond which the torque drops off, but the current in the stator increases. A knowledge of this characteristic may prove valuable to the operator who has had difficulty in causing his motor to lock into synchronism, or finds the current drawn excessive for his supply system. 